\title{
What Do You Mean by Trust? Establishing Shared Meaning in Interdisciplinary Design for Assistive Technology
}

\author{
Isabel Schwaninger ${ }^{1}$ D $\cdot$ Florian Güldenpfennig $^{2} \cdot$ Astrid Weiss $^{1} \cdot$ Geraldine Fitzpatrick $^{1}$
}

Accepted: 22 December 2020 / Published online: 6 June 2021

(c) The Author(s) 2021

\begin{abstract}
The topic of trust has attracted increasing interest within HRI research, and is particularly relevant in the context of social robots and their assistance of older people at home. To make this abstract concept of trust more tangible for developers of robotic technologies and to connect it with older people's living spaces and their daily practices, we propose a light-weight method drawing on elicitation cards to be used at early stages of participatory design. The cards were designed to serve as a guide for qualitative interviews at ideation phases. This was accomplished by using the cards connected to the living spaces of the participants, their daily practices, and 'provocative' questions to structure conversations. We developed the method with 10 inexperienced interviewers who conducted 10 qualitative interviews on the topic of trust without cards, and who tested the cards with 10 older adults. Our findings indicate that the method served as a powerful facilitator of conversations around the topic of trust and enabled interviewers to engage with everyday practices of older adults; it also facilitated a more active role for older adults during the conversations. As indicators of findings that can come from the cards, salient trust-related themes that emerged from the analysis of card usage were the desire for control, companionship, privacy, understandability, and location-specific requirements with regards to trust.
\end{abstract}

Keywords Trust $\cdot$ Robots $\cdot$ Older adults $\cdot$ Elicitation cards $\cdot$ Ideation $\cdot$ Participatory design $\cdot$ Interdisciplinary research teams

\section{Introduction}

As socially assistive robots are being developed to support older adults' independent daily living in the Global North, they are considered to enter everyday lives, homes, and intimate spaces of people. The actual use of such robots is thus entangled with very sensitive contexts and interaction experiences, which brings in trust as a relevant quality criterion for people to sustainably interact with assistive technology. However, what constitutes trust in a robot for an older adult can be very challenging to grasp in practice, and research suggests that older adults are more likely to use a language of distrust to refer to the development of technology in society as a whole [32].

Capturing qualities and notions of trust in socially assistive robots by older adults is challenging. However, the

Isabel Schwaninger

isabel.schwaninger@tuwien.ac.at

HCI Group, TU Wien, Argentinierstr. 8, 1040 Wien, Austria

2 New Design University, Mariazeller Str. 97a, 3100 St. Pölten, Austria even bigger challenge occurs when we try to transfer these notions into conceptual designs and robotic prototypes [60]. As empirical research in human-robot interaction (HRI) requires interdisciplinary teams (e.g. gerontologists, social scientists, and engineers), knowledge transfer may also come with a significant loss of knowledge (e.g., when social scientists do requirement studies that engineers should later build on). While participatory design approaches involve older adults in the conceptualization of novel robotic systems $[11,34,36]$, we witness a gap between the understanding and the making. Reasons for this can be an overestimation of a robot's capabilities by older adults or a lack of technological readiness to implement desired functionalities [59]. However, it might also be caused by a lack of participation of developers at early stages of ideation and conceptualization [23].

It is crucial that developers gain their very personal feeling and understanding of trust from the perspectives of their target users [29]. However, the concept of trust in relation to socially assistive robots is abstract and it can be hard for engineers and older adults alike to talk about related sensitive topics such as privacy and intimacy. Moreover, conducting 
in-depth interviews to elicit ideas about future robots needs a lot of training and might be challenging for developers working in a multidisciplinary engineering field. We lack a participatory design approach that offers a low-threshold way for developers to gain a holistic understanding of contextual issues around people's everyday lives in their living spaces and its relation to trust as a quality criterion for a socially assistive robot.

Hence the aim of our research is to develop a method for facilitating conversations and early engagement of older adults with developers and programmers of robots in order to establish a mutual understanding of topics related to trust. We do this by taking into account people's social practices and by exploring places in people's homes. We designed a deck of elicitation cards that should on the one hand give older adults an active role in the ideation of novel robotic technology, and on the other hand empower developers with little training to conduct in-depth interviews and learn about the complex socio-material system in which a future innovation should be integrated. We demonstrate how this was accomplished by involving inexperienced interviewers (i.e. master-level Informatics students) in the design of the cards and a proof-of-concept study.

This article offers two main contributions: I, a deck of elicitation cards as a new method for participatory involvement of older adults and developers in the ideation phase for assistive robotic systems with a special focus on trust and places in the home; and II, illustrative findings on trust and imaginaries of robots in people's living spaces as facilitated by using the cards.

The outline of this article is as follows: In the next section, we review related work on people's practices and trust and on involving older adults in the design of robotic technology (Sect. 2). Subsequently, we present how we created our deck of cards in several iterations (Sect. 3), followed by our findings on the cards as method, as well as on the topics and notions on the relations of places, people, technology, and trust derived through using the cards (Sect. 4). After (Sect. 5), in which we reflect on the usage of the cards and suggested redesigns, as well as potential implications for conceptualizing robotic technology in a next phase. We close the article with a section on (Sect. 6).

\section{Related Work}

\subsection{Trust in Robots and People's Practices}

The notion of trust in robots draws on how trust has been framed across various different research disciplines. Trust in robots has also been referred to as taking risk-based approaches [61] or as reliance [10,28], taking into account human characteristics (such as ability and personality), envi- ronmental characteristics (such as task and team) and robot characteristics (such as performance and attributes). Further, previous empirical studies in HRI have drawn on the concept of interpersonal trust [41] to study people's trust in a robot [40], where trust is connected to another party's competence, benevolence and integrity [41]. As trust in robots will be also interwoven with people's everyday practices [51], it might be advisable to take these into account as a starting point [33,63].

An orientation to practice has also become a key element of different schools of social science thinking, and has been taken up in Human-Computer Interaction (HCI) and in Computer-Supported Cooperative Work (CSCW), also with regards to trust $[16,53,62]$. In contrast to rationalistic or structurally deterministic interpretations of social interaction, practice approaches explore "[...] historical process and performances, longer-term actions which persist over time, and which must be studied along the full length of their temporal trajectory[,][...] situated in time and space" [33, p. 3543].

We argue that for trust research and in particular in ideation phases of developing robots, there is also a need to move towards a more practice-orientation, attending to the situatedness and multidimensionality of this complex and context-dependent topic. A practice-based approach will also enable us to gain a more holistic and situated understanding of people's experiences and notions of trust, and how it may play out dynamically in the social world. This requires us to look beyond the dyadic interaction between a single person and a robot and thus use methods that enable both researchers and engineers, and people who may potentially use robots, to explore the topic in more depth. Complementing experimental set-ups (e.g. [1,46,64]) and the use of trust scales (e.g. $[13,49,57])$, qualitative methods have been used in previous work on trust, indicating interesting relationships such as between trust and people's willingness to use a robot, as well as between trust and information provided to people about a robot [43].

However, trust itself is methodologically challenging to tackle (and certainly difficult to quantify [47]), and it may come with pitfalls: In a study by Salem et al. [47], study participants followed a robot's instructions not only because of actual trust, but also due to the novelty effect or because of participating in an experiment, further considering the robot to represent or be an extension of researchers [47]. Therefore, methods need to be developed to carefully take into account multiple facets of trust and allow an exploration of the topic from end users' perspectives.

With regards to taking open-ended approaches to trust, there have been insightful studies about trust in the context of healthcare outside of HRI that involve ethnography or in-situ interviews (e.g., in healthcare [14] and in HCI [16,17,58]). Related to care and robots, Stuck et al. [55] conducted qualitative interviews to investigate trust in robots as caregivers. 
The researchers confronted their participants with four predefined and fictive scenarios (e.g., receiving assistance while taking a bath) in order to derive findings from speaking to older adults who received regular care by human caregivers.

This study by Stuck et al. [55] can be seen as a first valuable step towards involving older adults at an early stage of design by talking to them about predefined situations. Still, this approach may carry apriori assumptions from the researchers, and it is not designed for diverging from the predefined conversational paths. We argue that there is a need to additionally take a more open-ended look at sites of care and people's (social) practices in initial phases of participatory research, i.e., ideation phases. Therefore, we need to develop methods that enable inexperienced interviewers like engineers to address older people's concerns more easily and in an ethical way, and that provide some guidance while at the same time allow them to shape the direction of the conversation to facilitate people-centered conceptualizations of trust and robots.

To inform ideation of trust and robots, we argue that it will be beneficial to start from people's social practices, and to facilitate a shared understanding between researchers and end users about their overall attitudes and potential acceptance of social robots. We argue that research will benefit from considering people's social practices and providing a more holistic understanding of how trust may play out dynamically in the social world. We also argue that it a useful side effect is having senior people who know how to talk about a difficult topic like trust in robots and so can engage more effectively in co-creating their futures.

\subsection{Participatory Methods in HRI}

Involving people at an early stage of design and conducting research in real-world settings is of crucial importance in user-centered (UCD) and participatory design (PD). When it comes to robots however, this is difficult to accomplish with traditional UCD/PD methods, given that building prototypes requires a lot of technical expertise and decisions about which lay people have no familiarity. Designers and engineers of robots who do make these decisions, on the other hand, most likely experience life from a different perspective than their target group of older people [27].

For older adults and robots, some recent projects have involved people in research at an early stage of developing robots, i.e., through participatory design $[11,24,34,36]$. Among the recent work on participatory design with older adults and robots, Lee et al. [36] focus on the support of mutual learning between researchers and participants, and on promoting active participation of older adults in design. Lan Hing Ting et al. [34] use ethnographic methods to explore the co-design and evaluation process of a mobile social robotic solution for elders following a living lab approach. Multi- ple perspectives of people are involved in design: the people who are considered the primary users, sociologists, designers, and engineers. In prototyping workshops, Brathen et al. [11] found that developing a story about a robot in the context of older people's homes and in the daily life of older adults is essential for successful design and prototyping.

While ethnographic methods can be very fruitful for design, they are often not feasible, for example, due to a lack of expertise, or due to an extensive amount of time needed and, consequently, due to costs [42]. Hence, methods that support qualitative or ethnographic interviews in innovative ways may also be useful instead of running a full ethnographic study. However interviews are also not without their challenges in this context. First of all, exploring sensitive topics can be difficult to discuss in conventional formal interviews, especially for people with little training in qualitative research. Envisioning abstract concepts or new technologies is also a challenge especially when engaging with older adults $[2,39]$. Here, additional visualization techniques may be able to support elicitation of related difficult topics [54] such as trust. They can "become bridges between strangers [...] [and] function as starting and reference points for discussions of the familiar or the unknown" [15, p. 99]. Elicitation techniques can also reduce power imbalances between researchers and interview partners, and they can enhance participants' ability to elaborate on their own conceptions of the world [7]. Playful methods can also support participants' engagement and active participation in studies, for example, when doing cultural probes [9]. Further, interviewers or designers with little training can benefit from playful methods [54] for co-design.

Examples of tools for elicitation include photographs [15], as well as collaborative card-based techniques, which already have a long tradition in participatory design. Cards can be used to increase user involvement and investigate different aspects of design [8].

Previous work developed visual representations and made design knowledge accessible to diverse actors like researchers, designers and various research partners. In the field of HRI, Lee et al. [37] used collaborative map making as a reflexive method for understanding matters regarding computing technologies in the home, and for visualizing social actors. Visual representations of the home have also been fruitful for discussing social dynamics and roles with regards to home automation [35]. Further, video representations of robots can be useful tools, as they can support elicitation of activities of older adults and scenarios of how a robot may enhance people's quality of life [4].

According to a recent systematic literature review on analogue tools for collaborative ideation, cards (i.e. in the form of card decks and card games) dominate the currently available design tools (i.e. tools for designing technologies or digital artifacts or services) [44]. IDEO [31] was the first to popularise the method deck format in 2003 [44]. Other work using 
cards includes decks to inform sound design in games [3], or tangible learning games [18]. Cards can be used both to evaluate existing tools and to inform design of new platforms [21], as well as for understanding current concerns from the perspective of diverse actors [37].

While cards dominate the currently available design tools, Peters et al. [44] also found a significant gap for tools to facilitate inclusion of diverse participants into the design process, such as people with accessibility issues. When it comes to Artificial Intelligence (AI), they further found that there is a gap of tools for imagining AI futures for a diversity of users, as, for example, the percentage of users with disabilities may be growing [44]. Although Ballard et al. [5] developed a card-based tool for industry product teams to surface ethical concerns related to AI technologies, this tool is not specifically designed to use with older people nor about social robots. While we consider awareness of ethical dimensions of emerging technologies from the perspective of industries as important, there is to the best of our knowledge no tool that takes into account older adults' daily routines and social practices in people's living spaces, with the aim to tackle design challenges around trust in robots.

\section{Research Approach and Methods}

As elaborated in the previous section, research on trust in robots raises challenging questions on several layers. Firstly, trust is abstract and difficult to get at in participatory design processes, especially for researchers/investigators with little experience in qualitative research, and there may be challenges in knowledge transfer from ideation phases to conceptual designs and robotic prototypes. Secondly, there is a lack of knowledge on the topic of trust in robots in the context of older people's homes with respect to their everyday life practices and specific places in their homes.

To tackle these challenges, we developed a novel approach featuring elicitation cards that we created for use in the early phases of a participatory design process, i.e., ideation and conceptualizations of trust and robots. Hence, the purpose of our research is to propose a method with a novel application to the issue of trust, robots and older people (the elicitation cards) and to provide a proof of concept (by means of unpacking the design process of the cards and running a proof of concept study). In doing so, we aim to answer two main research questions: I. How are the cards useful as a method for inexperienced interviewers for facilitating active conversations on trust with older people, and II. What can the cards reveal about trust and robots with older people in the context of older people's homes (cf. research contributions in the introduction section). To answer our research questions, we combined several methodological approaches across different phases, which we outline in the following subsections.

\subsection{Exploring the Challenge of Talking About Trust and Robots from Multiple Perspectives}

Talking about topics related to trust in sensitive contexts like people's living spaces can be challenging, especially for interviewers with no or little experience in conducting qualitative research. In line with our intention to create a research tool that will ultimately allow inexperienced interviewers to capture rich feedback when talking about trust, we decided to integrate multiple perspectives in the design phase of the elicitation cards. For one thing, we considered a theoretical perspective by incorporating insights from an in-depth literature review. For another, we let our own ideas as HRI researchers and interaction designers inspire the design work of the card deck, where we as researchers already had previous experience with conducting interviews on trust in care contexts. Finally, to create and validate the method as a useful tool for inexperienced interviewers, we involved master-level Informatics students in the process, who had little experience in qualitative research. Those students, however, had theoretical knowledge about the topic of trust and robots, since they all attended a course called HCI and Healthcare, which covered corresponding research areas.

To explore practical challenges of conducting more traditional semi-structured interviews around trust and robots in this sensitive context, and to provide comparative data with and without using cards, we asked 10 students from the course (HCI in Healthcare) to form pairs and first conduct 2 exploratory semi-structured interviews with interview guidelines and audio recorders per pair. This resulted in 10 interviews in total (i.e., 10 students conducted exploratory interviews with 10 interview partners in total). The interviews centered around the topic of trust in robots for the home with people of any age group, which also included questions about a typical day of their interview partners. The interviewees were further asked by the students to imagine they had a robot in their homes, and how this robot could support or disturb them. With these first semi-structured interviews, we (and the students) deepened our sense of the challenges of conducting interviews about the topic of trust in robots.

In these exploratory interviews, we also encouraged the interviewers to explore terminology around using the term robot in conversations, as previous research suggests that people's perceptions of robots can draw on what is perpetuated by the media and entertainment industry $[6,48,56]$. They started the conversations using the term latest invention, i.e., a term other than robot, to see if it would allow more abstraction, and introduced the term robot at a later time if that suited the conversation flow. 


\subsection{Designing the Cards}

Drawing on the literature and on previous experiences, we (the lecturers) moved on to create the elicitation cards. It took several iterations to create the final deck. The students were involved in designing an initial version of the cards, which we further developed and which were tested by the students later with older adults.

In the initial round, the 10 students designed 42 cards. In detail, they based their ideas on lecture discussions and literature on trust, robots, robots in homes, robots and Active and Assisted Living (AAL), and robots and older adults, along with the first exploratory interviews they conducted. We asked them to each design at least 3 and up to 5 cards. At this point, the instructions for the students left enough room for their own ideas. Based on discussions in class, we agreed that the cards could refer to the topic of trust in multiple ways (i.e. a robot's trustworthiness as reliability [10], its competence, integrity and benevolence [41], and in relation to people and context). Because we were interested in matters around people's social practices , as well as contextspecific aspects, these initial cards would refer to one of the following five topics: people's roles, motivation and skills, context, interaction and communication, robot's appearance and behavior, and robot's roles. The cards would contain provoking questions, such as "What if the latest invention knew to stay away when other people are around?", or "What if the latest invention speaks your native language?".

We (the lecturers) carefully reviewed and discussed the cards submitted by the students and used them to develop a next version of the deck of elicitation cards. In this second round, we opted for creating 5 categories of cards. At this point of time, it also became evident that the students, and we too, wanted the cards to be used in a more playful manner in the qualitative interviews. We also designed simple game mechanics (see later section about playing with the cards). The 5 categories included the Golden Card, the People Card, the Places Cards and the Provocation Cards (see Table 1). We designed the People Card to explore the social life of the interview partners, and we created the Motives Card to talk through a typical day and routines. The Golden Card was designed to ask for general ideas about how people imagine to be supported or disturbed by a robot. We also designed a tangible coin-shaped token to help imagining a robot at different places in people's homes during the conversation, with the words latest invention engraved.

The Provocation Cards contain questions regarding a latest invention's design cues and the interaction with a robot. The Provocation Cards are based on the initial questions submitted by our students, asking provoking questions that aim to stimulate discussions, which refer to two trust categories (see Table 2), namely interpersonal trust from organizational theory [41], and reliance [10]. We apply the concept of inter-
Table 1 Card categories and the content of the cards

\begin{tabular}{ll}
\hline 2 Golden Cards & Questions about support/distraction \\
1 People Card & Questions about social life \\
1 Motives Card & Questions about motives and plans \\
8 Places Cards & 5 figures of rooms; 3 empty cards \\
24 Provoc. Cards & Questions about robot design \\
\hline
\end{tabular}

personal trust to how people would trust a robot (as it has been done in previous research [40]), as well as how people would trust the people behind a robot, such as programmers (as found e.g. by Salem et al. [47]), or healthcare professionals when the robot collects data about a person's medical status.

\subsection{Playing with the Cards}

Since the resulting cards are intended to serve as a research method, we go on to describe how we used them in more detail. The use of the cards is also illustrated in Fig. 1.

The cards were designed to be played within a person's home. As an initial activity, the interviewer and the older person together lay the Places Cards out on a surface so that they visually represent the layout of the home of the interview partner. The Places Cards include a living room, a kitchen, a bedroom, a toilet and a bathroom. Additionally, empty cards can be used to draw up additional places that are not covered by the deck of cards.

To then gain more contextual information, two additional cards are introduced: the People Card and the Motives Card. The People Card contains questions to explore the social life of the interview partner, asking who they live with, whether they have any children, partners, pets, or friends, and whether there is anyone coming to their home to take care of them or the home on a regular basis. The Motives Card is then drawn and this prompts them to talk through a typical day, about plans for such a day and future life.

After this floor plan preparation and these initial questions have been asked, the next phase can start. The golden token, the Golden Card and Provocation Cards are used in a playful manner. The golden token is used to represent a latest invention, and it is moved from place to place on the floor plan, 'walking' from Place Card to Place Card, as a person would go from place to place on a typical day.

At each place, the Golden Card is used, asking generally how a latest invention could support the older adult at this place, and how it would disturb them. Subsequently, the older adult randomly pulls 1-3 Provocation Cards. For each Provocation Card, the question written on the card is asked, and the idea of a latest invention (with specific trust-related behaviours as facilitated by the Provocation Cards) at the specific place is discussed. The questions on the Provocation 
Table 2 Provocation card questions and associated trust categories, namely interpersonal trust (I) [41] including benevolence, competence and integrity; and reliance (R) [10] with human characteristics, robot characteristics and environmental characteristics

\begin{tabular}{ll}
\hline Provoking questions & Trust \\
\hline What if the latest invention ( $L I$ ) has microphones? & $\mathrm{I}, \mathrm{R}$ \\
What if the $L I$ is connected to your bank account? & $\mathrm{I}, \mathrm{R}$ \\
What if the $L I$ knows about your medical status? & $\mathrm{I}, \mathrm{R}$ \\
What if the $L I$ can detect when an emergency happens? & $\mathrm{I}, \mathrm{R}$ \\
What if the $L I$ has a personality similar to your own? & $\mathrm{I}$ \\
What if the $L I$ makes mistakes sometimes? & $\mathrm{R}$ \\
What if the $L I$ watches you do things? & $\mathrm{I}$ \\
What if the $L I$ can detect when you are very happy? & $\mathrm{I}$ \\
What if the $L I$ is capable of expressing emotions? & $\mathrm{I}$ \\
What if the $L I$ can detect when you are not feeling well? & $\mathrm{I}$ \\
What if the $L I$ has cameras, and other people can see what the $L I$ sees? & $\mathrm{I}$ \\
What if the $L I$ has very cute eyes that are cameras? & $\mathrm{I}$ \\
What if the $L I$ is very strong, so that it can lift things? & $\mathrm{R}$ \\
What if the $L I$ can understand you speaking, and what if it records everything? & $\mathrm{I}, \mathrm{R}$ \\
What if the $L I$ breaks something you like? & $\mathrm{R}$ \\
What if the $L I$ can make phone calls to other people? & $\mathrm{I}, \mathrm{R}$ \\
What if you cannot turn off the $L I ?$ & $\mathrm{R}$ \\
What if the $L I$ is very talkative to everybody around and cannot keep a secret? & $\mathrm{I}$ \\
What if the $L I$ doesn't speak your native language, or has a strange accent? & $\mathrm{I}$ \\
What if an emergency happens, and the $L I$ does NOT detect it or cannot help? & $\mathrm{R}$ \\
What if the $L I$ is made of a very comfortable material, e.g. fur? & $\mathrm{I}$ \\
What if the $L I$ becomes a companion? & $\mathrm{I}$ \\
\hline
\end{tabular}

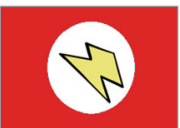

The Latest Invention (LI) piece or token marks the current position

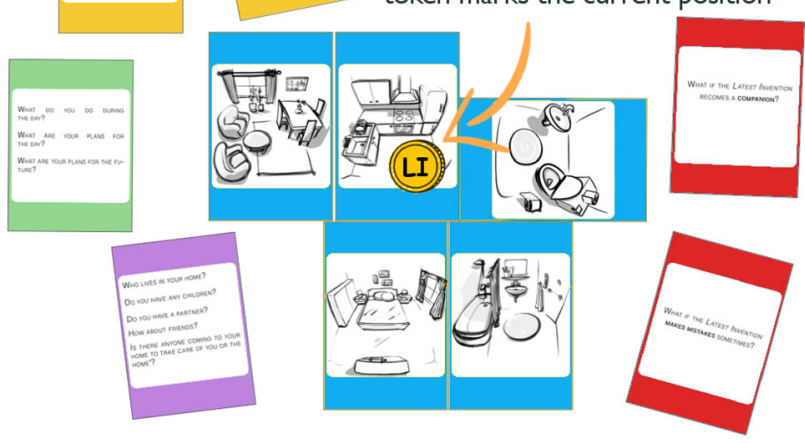

Fig. 1 A laid floor plan (blue) with a golden coin-shaped token, two Golden Cards (gold/yellow), a Motives Card (green), a People's Card (purple), two Provocation Cards (red) and a staple of Provocation Cards (red with a flash). (Color figure online)

Cards are answered specifically referring to the places the latest invention is at in the current state of the conversation. Our aim is for the cards and the token to elicit trust-related aspects that specifically situated in places and people's everyday practices.

\subsection{Collecting Empirical Data on Using the Cards}

To provide a proof of concept, i.e. use the cards with both older adults and people with little experience in doing qualitative research, our students were asked to form pairs and conduct two qualitative interviews with older adults of age $65+$ per pair. This resulted in 10 interviews, which lasted 30 $45 \mathrm{~min}$ each. The interviews were conducted mostly with older relatives or neighbors of the interviewers, while two students also approached people on the street to participate in a study.

Among the 10 older adults, $75 \%$ were women, and all were above 63 , with a mean age of 71.1 , and a standard deviation of 5.6. They lived in cities (5) or villages (5) in central Europe, and their self-reported technical affinity tended to be low. The interviews were conducted in three different languages, depending on the interview partners' mother tongues. The students took notes on how people interacted with the cards and the content of the conversations, or they audio-recorded and transcribed the interviews in English. As the cards were all labelled in English, they were translated by the students in the course of the conversations if they were carried out in a language other than English.

To report on the use of the cards, the students were then asked to give 30-45 min presentations on their data, followed by class discussions. The presentations and dis- 
cussions were audio-recorded, and the lecturers took notes during the class. The presented data included demographic details of their interview partners, and empirical observations of the cards being used and the findings from the interviews. They were also asked to connect the findings to the literature, and draw out first ideas about implications for designing trustworthy robots, as well as some meta-reflections. The meta-reflections included their overall experience, challenges and suggestions for changing the cards, and reflections on the differences when using the cards vs. not using them in the previously conducted semi-structured interviews with people of any age group.

We also interviewed the students after their presentations, as we were interested in their experience as investigators. The questions we asked touched on both methodological and content-related reflections, focusing on the students' experiences. We were mainly interested in how the cards (i.e. each card category and single Provocation Cards) were useful for the conversation flow, and how they would suggest improving the cards. Further, we asked about the trust concept and contextual matters, the terminology regarding the the term latest invention vs. robot, people's daily practices, and design implications.

To give some concrete examples of our questions, we asked the students about their strategies for getting the conversation going, what aspects of the Places Cards they found most useful, how they experienced talking about trust, and what they found were the key dimensions of trust in the specific context. We asked them to explain in more detail their experience with the term latest invention vs. robot. We were also interested in whether and how they were able to talk about any concrete examples of the robot disturbing or supporting people. We asked them what they had learned about robots in homes from conducting the interviews, and what would be the key features they would recommend to somebody who would want to design for trust in robots.

\subsection{Analyzing the Data}

We drew on different layers of data to address our two main research questions, making use of topic analysis [25].

For answering the first question, how are the cards useful as a method for inexperienced interviewers for facilitating active conversations on trust with older people, we incorporated diverse data: the presentation slides submitted by the students; and the notes and recordings of the oral presentations and discussion in the course. Both the slides and the discussions included a meta-reflection on the method. For additional insights on the method, we also referred to the analysis of the content of the discussions rather than only the meta-level reflections.

For answering the second question, what can the cards reveal about trust and robots with older people in the context of older people's homes, we drew on the submitted transcripts and notes of the interviews with and without cards. We also analyzed the presentation slides and the class discussions.

In the course of topic analysis [25], we placed all text passages from the transcripts and the notes we had taken at the final presentations of the projects into a spreadsheet, one paragraph per cell. Most of the notes were already paraphrased sentences of the conversations. We printed them out, cut them into pieces of text passages and added recurring themes to each text passage.

In repeated rounds, we looked for subcategories of these theme categories and pre-identified central elements of a theme. In the next step, we added the most important characteristics of each theme to each text paraphrase. We also took into account whether a certain topic was introduced by the interviewer or by the interview partners, as this can give insights into the meaning of a theme for the interview partners. In the next step, we identified commonalities and differences within the themes across the interviews.

\section{Findings}

\subsection{Playing with the Cards: The Cards as a Method}

The first part of our findings conveys insights about our deck of cards as a qualitative research method for participatory design at the ideation stage. We found that the cards helped to create a fluent conversation and to establish trust between interviewers ${ }^{1}$ and older people. ${ }^{2}$ Furthermore, using the cards facilitated active participation and a deeper reflection and learning effects for the older interviewees, while also promoting detailed discussions about topics around the home, trust, and social robots.

\subsubsection{Creating a Fluent Conversation and Trust}

The interviewers, who had no or very little experience with conducting qualitative interviews, reported a positive impact of the cards on the conversation flow ("there was a red thread throughout the conversation and a structure" (I2), "otherwise, how do you keep a red thread?" (I5)). They found the cards "easy to understand, and it was easy to explain to others [i.e. interview partners] what the cards were about" (I1). The students reported that the cards made the conversation appear more relaxed and like a game, even entertaining, and helped in "keep[ing] the conversation rolling" (I5). The interviewers discussed this in contrast to their experience of having such

\footnotetext{
${ }^{1}$ Note, in this section, we use the notions of interviewers and students synonymously, since the students conducted the interviews.

2 The older participants who described their homes and attitude towards robots are denoted as older adults, older people, interviewees or the like.
} 


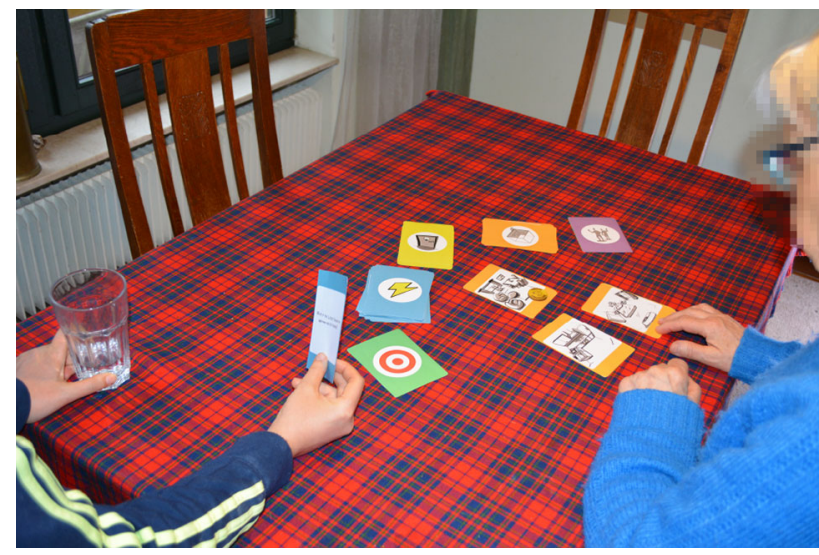

Fig. 2 A printout of the elicitation cards in use (version 1)

conversations without cards, where they found a tendency that the "conversation died out" (I6) when not using the cards. Figure 2 shows a conversation based on card use.

Our findings also point to ways in which the cards helped to establish trust between interviewer and older interviewee, and using the cards made the conversation personal (e.g., "in the beginning I thought she [the older interviewee] had a good life [...] but later I realized [...] she was really alone" (I5)). The cards gave access to imagined actions in intimate spaces, practices and emotional dimensions in stories around older people's everyday lives ("when we talked about the bedroom, she really talked about it [...] [how] she combed her hair [...] maybe if we didn't specifically refer to the bedroom, I couldn't talk about this aspect" (I6)). To illustrate the emotions conveyed, an interviewee said, "I always need someone to care about me [...] and it's the greatest fear of my life" (I3), and another older person stated, "the floor is also wet and I'm afraid to fall" (I4) in the bathroom. Another interviewee said they may be ashamed if they or their private space were filmed by a latest invention.

\subsubsection{Active Participation and Mutual Learning}

The Provocation Cards and the Places Cards appeared to be the most fruitful for promoting active participation of the the older adults. Laying out the floor plan served as a shared task for the interview partners and established a common play ground ("they [the elicitation cards] helped us and the participants to imagine the house and not skip or miss some rooms" (I2)). The older interviewees frequently followed the invitation to pick up Provocation Cards (up to three cards per place), indicating their active participation in the conversation.

The cards also facilitated additional points of reflection, so older adults were able to develop and revise their ideas. People happened to change their minds in the course of the conversation when talking about concrete scenes with a robot at specific places. The cards thus had an educational effect, where older people were able to reflect more on what they wanted to have in their private space.

Furthermore, the interviewers (and researchers) learned about the challenges of talking about trust, as well as about the domestic environments of older adults. They learned about the home and the social context in older people's lives, and engaged in an active dialogue with older adults about older people's concerns.

\subsubsection{Facilitating Detailed Insights}

Overall, the interviewers reported that the cards added focus to the stories told by participants and thus helped to reveal details (in particular compared to conducting interviews without cards). For example, some older interviewees initially said they had few or no reservations regarding privacy. However, by means of the cards, older people later detailed in which places video recordings were acceptable and where not: "[It is] no problem if the latest invention has cameras and other people can see what the latest invention sees, except for the bathroom and the toilet, she [older interviewee] does not want to be recorded there" (I8).

It was sometimes surprising how much detail was included in the concrete scenarios with robots that interviewees talked through, e.g. an interviewee saying the robot "must not spill the bucket" (I4) when cleaning the rooms, or another older person stating that, they "could as well play a card game on a robot [but] would not want to reach out too far" (I9), and it "should be comfortably reachable" (I9), or the latest invention must have "a certain size to be able to reach things" (I6) in the kitchen. As the interviewers also had the experience of talking about a typical day and people's homes without using the cards, they found that the conversations without the cards, in comparison, tended to be less easy and lacked detail ("I think they could not have imagined it [without cards] as they did with cards" (I1)).

\subsection{Components of the Cards}

Since the cards had a positive effect on the conversations, it might be useful to unpack the components of the cards and analyse them each in more detail. These details highlight findings on the use of the token as well as particularities of each card category.

\subsubsection{The Token Saying Latest Invention: Challenges Regarding the Terminology}

Talking about robots per se tended to be difficult in the beginning, even when using the term latest invention. As stated earlier, we gave the students the opportunity of avoiding the word robot by instead introducing the notion of a lat- 
est invention (LI). The main motivation was not to create stereotypical robot images in the mind of the older participants (e.g., R2D2 from Starwars). While this term was used throughout the interviews in some cases, other interviewers found LI even more abstract, and instead introduced the term robot in the course of the conversations ("the latest invention was somehow confusing and they didn't understand it, and we should explain it" (I6)). On the other hand, some interviewers reported how it was hard to avoid the term robot at all ("they automatically thought about robots" (I2)). In the rest of the article, we will thus use both terms, indicating different strategies for handling the conversations.

Some interviewers drew on public media or movie characters to make assistive technologies tangible at first. Also, there were associations with known TV shows like Tom Turbo, an anthropomorphic bicycle ("[it could] make coffee like Tom Turbo" (I8)). One interviewer played a commercial voice assistant in different accents to demonstrate an agent's potential voice (e.g., saying, "Hey Siri, make some coffee for me" (I7)). In addition, the interviewers reported that it was useful to refer to utilities in the household and connect them to the floor plan in order to help imagining what the latest invention could be like.

Despite the interviewers finding initial difficulties when speaking about robots as unfamiliar artifacts, they also concluded that walking through the floor plans and thinking out loud through daily routines became easier throughout the conversations. Further, using the token (together with the Places Cards) acted as a common ground to get back on track ("otherwise, we would have forgotten plenty of things" (I5)). On the other hand, two interviewers reported how using the token was especially helpful in the beginning of the interview, i.e. "as an entry point [...] then, as the conversation was rolling, we did not need it any longer" (I1).

Students were surprised about the interviewees being so skeptical about robots. However, the interviewers encouraged older people to talk about specific scenarios, i.e. in relation to the places. To overcome the difficulties with the terminology, there were also suggestions for future work. For example, two interviewers suggested that it would be useful to provide older interviewees with information about technology like assistive robots beforehand, i.e. "it would be useful to have an additional set of cards, where these things are explained" (I5). As the interviewers also struggled with not knowing about their interviewees' background, another two students proposed providing cards around technical affinity to "ask them in more detail to know exactly what is their information about [...] robots" (I6).

\subsubsection{Introducing Other People with the People Card}

The People Card was intended to introduce other (significant) people of the older adults' daily lives to the conversations.
We found in our analysis that older adults talked about family members later in the conversations, as these family members had been brought into the discussion using the People Card. For example, an interviewee spoke about their grandson in the beginning when using the card. Later in the conversation, when the ability of the robot being able to make phone calls was discussed, the grandson was brought up again ("It would be nice if I say call my dear grandson and it does" (I9)).

\subsubsection{Talking About a Typical Day with the Motives Card}

The interview partners were discussing plans for a typical day and the lives of the older adults when using the Motives Card, and more in detail when walking through the floor plan. Talking through a typical day was thus facilitated by using the Places Cards in combination with the Motives Card. Upfront, older people described their daily routines (e.g., "wake up early, go in the bathroom. She [the older interviewee] drinks coffee and feeds the animals. [...]" (I8)). However, two older adults were surprised by the question about their plans for their life given they felt old for this question. The interviewers also found the Motives Card repetitive when walking through the floor plan later in the conversation ("the repetitive explanation about the daily life, [...] both interview partners said, I explained it already" (I5)).

\subsubsection{Discussing Detailed Place-Based Insights with the Places Cards}

Use of the Places Cards enabled the older people to imagine being in the corresponding rooms and discuss the activities that would happen there. Privacy aspects were introduced by the cards, and older people would differentiate between the rooms and associated preferences, e.g., by saying they would have "no problem for recording in the kitchen and if it [the latest invention] understands what you say [...] except for the bathroom and toilet, she does not want to be recorded there" (I7).

By using the floor plan, older adults were also able to talk about recent events at specific places. For example, one older person told the story about a "past burglary" (I3) that had once happened in their home, a theme that was taken up several times again later in the conversation when reflecting on how the robot could enhance safety (e.g., the option of a "secure and intelligent entrance door" (I3), and a latest invention that "consists of cameras in [the] whole house to observe and report an emergency would be again a good idea" (I4)).

The Places Cards were also tied to an older person's specific current life and how they imagined the future. For example, while mapping out the home, an interviewer said the "bedroom on the first floor will be a problem in later life" (I5). Consequently, the interviewee "liked [the] idea of 
using voice to trigger commands" (I5) to a latest invention that would serve as a hospital-bed.

\subsubsection{The Golden Card Revealing Details About Support in Housework and Personal Assistance}

The general question of how the latest invention could support an older person triggered the interviewees to refer to the home, often to housework (e.g., "no particular support [in the living room], besides assisting with] small interior changes or help cleaning" (I10)). The Golden Card was used for such general questions, i.e., how older people could be supported and distracted by a latest invention. Interviewees referred to very specific activities like help with cooking ("It would also be helpful if the latest invention can cook" (I4)), "carrying the garbage downstairs" (I1), vacuum cleaning, work in the garden, "help with picking up things from the ground to avoid bending down" (I10), or help with cleaning in the bathroom or toilet ("it can [...] dry the bathroom after the shower" (I9)). These answers indicated a general openness for support in housework. Despite the self-reported lack of technical affinity of most older people in our study, some of them were able to imagine a latest invention in their homes in quite some detail. For example, when bringing down the garbage, "several steps need to be overcome" (I1), so the latest invention would need to be able to climb stairs.

Interviewers also reported on specific ideas for personal assistance from their interviewees. For example, an interviewee who was sitting in a wheelchair elaborated how "getting out of my wheelchair to sit on the toilet is one of the most difficult things for me. It could help me to do it and especially help me to dress up" (I4). The Golden Card was thus sometimes useful to talk about personalized support and assistance.

\subsubsection{Strategies Using the Provocation Cards}

While the Provocation Cards did not suggest a strict order of questions, these cards had the most positive effect on the conversation flow according to reports of some interviewers ("It was way easier to ask provoking questions when using the Provocation Cards" (I1)). Interviewers reported that the Provocation Cards were "really good because we could use them and they were good for guiding the interview" (I2). However, other interviewers remarked how "it is difficult to keep a conversation fluent with such cards" (I3), and that "it was sometimes difficult to find the right question" (I6).

To be more responsive to the conversations flow, the interviewers came up with strategies for using the Provocation Cards. Interviewers created several piles of Provocation Cards with similar topics to choose from, such as voice or privacy. Other interviewers created "one [pile], where it was all about the robot, and the other one for more general ques- tions" (I5). This way, it was possible to "get back to a pile, when the situation escalated" (I6).

While most Provocation Cards stimulated the conversation, some interviewers found using two particular cards rather difficult and named them "conversation killers" (I3). The card asking, "What if the latest invention can detect when you are very happy?" was sometimes not understood properly. In such a case the participants responded: "and then what?" (I3). Students reported that the participants "came to a halt, and they did not know what to do with this question, and we did not know either" (I4). Further, some interviewers found the card asking, "What if the latest invention is furry?", difficult, as their interview partners could not imagine such a robot. Only one older person said they "would rather have something real to cuddle" (I4) (instead of cuddling with a furry robot).

\subsection{Topics Related to Trust, Robots, and Older People as Facilitated by the Elicitation Cards}

Besides findings about the use of the cards per se, we also have specific findings on the topic of trust and robots as facilitated by the elicitation cards. We provide the most significant insights that emerged from the topic analysis to further illustrate that the deck of cards was actually appropriate for revealing relevant, trust-related findings. These include (design) insights on trust that refer to privacy, control and companionship, as well as thoughts on limitations of what technology can provide for people's lives and the future.

\subsubsection{Privacy Throughout the Home}

An important dimension of trust centered around privacy. Privacy aspects were provoked by the cards, e.g., when asking older adults to imagine the robot having cameras or recording audio. Older people stated they did not want to be watched.

Often, privacy aspects were in reference to anthropomorphic robot design, e.g. "If it looks like a human, I don't have a comfortable feeling to be in the toilet and bathroom with him. I think someone is really watching me and I don't like this feeling" (I9). In this sense, the cards facilitated the interviewee imagining a robot in a very intimate place where they would undress or perform intimate activities, and hence raised concerns about any stranger, be it the robot or a person watching them mediated by the robot, being able to watch them in a potentially vulnerable state.

Moving through the rooms sometimes changed older people's acceptance of what the robot should be able to do. An older person stated they had nothing to hide, but as soon as they entered the toilet and the bathroom, they did not want cameras at all anymore ("No problem if the latest invention has cameras and other people can see what the latest inven- 
tion sees, except for the bathroom and toilet, she does not want to be recorded there" (I7)). The Places Cards apparently inspired the interviewee's imagination of the robot actually being there when performing actions like taking a shower. Another example is provided by a case where an interviewee was also saying she had no problems with the robot having cute eyes to make video recordings, which "would be okay" (I8). However, when asked, what if the robot accompanied them everywhere in their home, the older adult rejected the robot coming to the bathroom with them ("I want to go to the bathroom on my own" (I8)), adding "and also when putting on my clothes I don't need a robot $[, \ldots$.$] at intimate activities$ the robot shouldn't be there [...] it should stand in the corner and wait" (I8).

\subsubsection{Having Ultimate Authority Over the Robot}

A repeating theme regarding trust was control. The fear of a robot making autonomous decisions in one's home was encountered with the desire to have the ultimate authority over the robot. For example, an older person said, "one may be afraid that it will become autonomous and then do things that one actually does not want" (I7).

Older adults expressed skepticism regarding the robot's autonomy by indicating it needed a turn-off button ("if I cannot turn off the latest invention [... I] will throw it away" (I5)), a reset-button (in case of any erroneous behaviour) or the option to unplug it. Being able to turn off the robot was often a precondition for accepting a robot at all. One person said they would "place the robot in front of the door and lock it out" (I8) if the turn-off button did not work. Very often, the desire of ultimately being in control occurred in relation to privacy or spending money (e.g. "I rather do this myself" (I7)).

For trusting the robot, older people wanted the robot to explain its actions in a transparent way and to be able to communicate clearly ("I don't care about the voice, but it should be understandable" (I9)), because they wanted to be in control of the robot's performances. Control was especially important when it came to the robot spending money ("No, no, I don't want it at all" (I6), when being asked if the robot may be connected to a person's bank account), otherwise they were afraid of being robbed.

\subsubsection{Mixed Acceptance of Companionship}

While we designed the cards and the procedure of using them with an aspiration to give the latest invention a certain degree of agency, the idea of having a quasi-social relationship with a robot was only partly picked up or accepted. While some older adults spoke about companionship with a robot in a quite wishful manner, other interviewees refused this very idea.
The latest invention was mostly imagined as being quite social in the course of the conversations. An interviewee said there were moments when technology was not needed such as when somebody was visiting ("when someone is visiting, I don't need this invention anymore anyway, then I am so happy and want to be left alone with my friends and family" (I4)), or when you want to be alone ("[there are] moments where you want to be alone" (I3)). Not being alone when the robot is present indicates the robot being perceived social to some extent.

Human-robot companionship was brought up as an alternative to being with other humans, as loneliness turned out to be an issue for some older people (e.g., having "problems with meeting friends because of [my] high age, most friends unfortunately died" (I9)). One interviewer also reported that the People Card "made the interviewee depressed for a moment" (I6). Some older adults discussed how they imagined the robot to be involved in intimate relationships with them, as they wanted a companion to play or talk with ("I would be very pleased to have a playmate to cheer me up" (I7)), or a latest invention to discuss with what would be discussed with a partner, or even to "make a massage at the end of the day" (I8) when talking about support in the bedroom.

\subsubsection{Scepticism and Limitations of Technology}

Scepticism of future technologies and a notion of carefulness was also part of the conversations. On the one hand, older people said they would "not only rely on the robot" (I10) in cases of emergency if the robot was not trustworthy. Further, older adults said they would "first do a trial run for a couple of months" (I4) before actually relying on a latest invention. On the other hand, the interviewees anticipated limitations of technology for the future. Besides optimism in certain capacities, e.g. being able to interact via voice commands with technology in the future ("I think technology will then be advanced so it is able to understand me" (I8)), interviewees seemed quite aware of its limitations. This holds for socioeconomic issues like the digital divide ("People who need care nowadays did not grow up with technology" (I10)), and medical issues ("When a person has dementia, the robot will not be able to fix it either" (I7)).

\section{Discussion}

The aim of our research was to propose a cards-based methodology to help explore the abstract topic of trust in robots in the home, especially involving inexperienced interviewers and older adults and to make knowledge accessible as part of the participatory process of ideation. By this means, we aim to foster understanding contextualized issues that may be relevant for trust, and ultimately for designing for 
trust in robots in the context of older adults' homes in a way that it is especially accessible for those who are supposed to consider this knowledge in the technology development. Our findings suggest that the cards had a positive impact on the conversation flow for people with little experience in conducting qualitative interviews, helping to both literally ground and structure the conversations in the home. Furthermore, the cards led to quite elaborated and specific insights and older people were able to express their concerns about robots in their private spaces, and progressively discover what they were not comfortable with, in particular, in the context of their daily practices. In this section, we discuss our findings for the cards as a method, along with implications for using and re-designing them. We also discuss our findings around trust in relation to the literature as facilitated by the cards, and derive implications for understanding and designing for trust in situated human-robot interaction.

\subsection{Facilitating Conversations Around Trust: Implications for the Cards as a Method}

On a methodological level, trust in robots can be an abstract topic that is hard to get at, especially in intimate settings and with inexperienced interviewers. While the cards acted as a useful tool in many ways to guide the interviews, we also suggest a couple of changes related to single cards or entire card categories, drawing on our rich data (i.e. the interviewers' feedback and the interview transcripts). This section connects to our first research question, i.e. How are the cards useful as a method for inexperienced interviewers for facilitating active conversations on trust with older people.

\subsubsection{Elicitation of Trust, Engagement of Interviewers and Active Participation of Older Adults}

Our findings show that by laying out the floor plan of the older person's living space, moving the token and drawing the cards, both the interviewers and older people were able to establish a common ground for the discussions, and actively participate in the conversations. Older adults were thus able to express their desires and concerns around having robots in their homes and develop their own responses further as they moved around the home with specific provocations.

The positive effect of the cards is in support of previous research, indicating that such elicitation techniques can facilitate conversations on abstract topics [7] like trust. Furthermore, our findings are in line with previous work showing that visual representations of the homes can facilitate discussions on social dynamics and potential automated technologies in these contexts [35].

The cards as a method facilitated a detailed and nuanced engagement with the topic on several layers. Older adults were able to realize their own concerns and express them in the conversations, sometimes changing their minds throughout the conversations and exploring the topic from different angles. Interviewees changing their minds is an indicator for deeper reflections and explorations of a topic in diverse ways to uncover nuances. Being able to unpack these nuances is also depending on the skills of an interviewer, indicating this is a powerful method to conduct interviews. The interviewers further creatively tailored the flow of the conversations, as they reported different strategies of using the cards, such as creating piles of different topics of cards to be more responsive to the conversation flow and to be able to guide these better.

Throughout the project, the students learned about the challenges of talking about trust generally and specifically with older adults. As also shown in other work on participatory design of robots with adults by Lee et al. [36] who conducted workshops with robot prototypes, our interviewers were able to learn about domestic environments of older adults' and their experiences, ethical concerns and how they could imagine to use robots. While our method did not make use of any actual robot prototypes (compared to participatory research by Lee et al. [36]), our interview technique is especially light-weight and guiding inexperienced interviewers to learn about older adults' concerns.

Despite the fact that the older adults did not interact with an actual robot, they were able to imagine scenarios at specific places in a very detailed manner. This holds for describing the robot as a helper in the household, as well as for issues around privacy, control, understandability, and companionship. Hence the method may help to develop a story about the robot in domestic environments and in particular day-to-daylives of older adults, which is an essential part of successful participatory design of unfamiliar artefacts like robots for older people's and for daily lives [11].

The challenges regarding the terminology as indicated by previous research $[6,56]$ however could not be fully resolved. While some students and older adults found it easier to use the term robot in conversations, others were more comfortable using the term latest invention. Future work may tackle this challenge further, as we will also discuss in Sect. 6.

\subsubsection{Redesigning the Cards}

We presented a proof of concept study of the use of our cards as a method, with the aim to test the idea, to reflect on lessons learnt and gather ideas for how to improve the method in a next iteration. In this subsection, we therefore suggest how the cards might be redesigned based on our empirical findings and literature. Slightly re-framing some of the questions or changing the cards might make them more suitable for different researchers or interviewees.

As stated in our findings, all card categories were found to be beneficial. However, the Motives Card, which was 
intended to guide the interviewee through a typical day, ended up being repetitive when used before walking through the floor plan with the token. We therefore suggest to use the Motives Card in conjunction with walking through the floor plan and not as its own distinct activity. Consequently, in future work we propose asking only one question on the Motives Cards: "What do you do on a typical day?". Optionally, as some interviewers were also missing information about their interview partners' technical affinity, we might also ask: "What technology if any have you used recently?".

As stated earlier, some challenges connected to the term robot were only partly resolved by means of the wording latest invention on the token. As avoiding the term robot was helpful for some interviewers, others found the term latest invention too abstract, and even using the term robot caused difficulties without giving specific examples such as referring to robots from popular movies. Still, other interviewers revealed rich reflections from the participants that might have been spoiled using the term robot or providing more details about what such a robot technology could look like. Therefore, we suggest keeping the term latest invention on the token and on the cards as it allows space for both interviewers and the older person to interpret it as make sense within the specific conversational context.

In the context of an abstract topic like trusting robots that people have no experience with, the interviewers found one particular Provocation Card rather difficult use. This was "What if the latest invention can detect when you are very happy?". Therefore, we suggest removing this Provocation Card. In case interviewers would also aim to explore more interaction modalities with a robot, two additional Provocation Cards may be added, i.e. one asking, "What if you could speak to the latest invention?", and another one asking, "What if you could use touch to interact with the latest invention?". In total, this would result in 25 Provocation Cards.

While some interviewers found the Provocation Cards helpful to structure the conversations, others stated that the questions on the cards would sometimes interrupt the flow. When facing such problems, they were very inventive and successfully created piles of cards covering similar topics. As we had mixed findings for the Provocation Cards in whether they were perceived useful with or without creating piles, we suggest that piles may be created by interviewers if needed, however, we would make this an optional step in setting up the game.

In summary, the cards facilitated conversations around trust in sensitive spaces, enabling people to reflect on how they may be supported in their homes by robots as well as the limitations of this support. We consider that this methodological innovation for design as participatory practice is a step towards more effective engagement and mutual partnership between older adults and the research community, and to facilitate ideation and conceptualization of trust in humanrobot interaction.

\subsection{Context-Specific Trust in Robots Unpacked: Implications for Conceptualizing Robots}

Through the data captured from use of the cards, we were able to identify detailed and context-specific insights around trust as well as around people's concerns in general as facilitated by having conversations about trust, which we will discuss in this subsection. This connects to our second research question, i.e. what can the cards reveal about trust and robots with older people in the context of older people's homes.

\subsubsection{Unpacking Multiple Dimensions of Trust}

The analysis points to multiple dimensions of trust that are relevant in the context of the home. Trust played out by using emotional language, referring to sensitive spaces and to privacy. As described in our findings, communication with the robot, companionship and being in control also turned out to be relevant for trust. Furthermore, trust may be connected directly to how people relate to places, i.e. in their living spaces.

Having a robot entering one's personal space thus involves exposure of the diversity of one's personal activities. This connects to the literature, where interpersonal trust is defined by Mayer et al. [41] as a person's willingness to be vulnerable. Our data adds to this vulnerability aspect by showing that a person's willingness to be vulnerable is not absolute or abstract, but instead very nuanced and situated. On the other hand, the control-aspect raised a lot of concerns in the course of the discussions, and according to the model of integrative trust by Mayer et al. [41], trust is defined as a party's willingness to be vulnerable irrespective of the ability to monitor or control the other party. With robots however, the desire for control was one of the central themes, which may be the case due to little trust.

The robot's capabilities (e.g. in housework) and its reliability were also important aspects of trust. This connects to previous literature on trust as reliance $[10,28]$, also referring to robot-related cues as one of the three aspects relevant for trust. Furthermore, a definition of interpersonal trust by Mayer et al. [41] defines a trustee's competence as one key element of trust.

However, framing trust as reliance also states that personrelated and environment-related cues have an impact on trust (reliance) in robots $[10,28]$. We found that the places in a home can make a difference in how a robot may be perceived, and what design cues people are willing to accept in the course of our conversations. Our findings may therefore be a building block for considering different places in a home for highlighting the complexity of trust, which may be 
inseparable from qualities of relationships between people, spaces, activities and values.

From a sociological point of view [38], our findings further point to notions of trust based on both cognition and affect. The use of emotional language and imaginations of companionship with a robot connects to trust based on affect rather than mere cognition (e.g., knowing about an other party's competence), which may point to potential relationshipbuilding with a robot beyond it being a mere tool (e.g. for use in household). Affect-based trust is an emotional dimension of trust next to a cognitive dimension [38]. Previous research investigated traits of a social robot to be aligned with cognitive and affective trust [26], and our research indicates that these different notions of trust can be revealed also by earlier engagement of inexperienced interviewers with older people's social practices and a light-weight method like cards. Engaging with people's needs in relation to social robots points to both emotional and cognition-based aspects and hence trust to take into account in the process of participatory design.

Engaging in conversations about trust may be also insightful for the interviewer to learn about older people's social context and how they relate to this context in general. For example, in discussing different levels of acceptance of robots at different places, we learned about how people may relate differently to places, also depending on who would be around (e.g., visiting friends or family members). We argue that engaging with the question how people relate to their context may be worth further investigation (see e.g. [52]) when aiming to design technology to be used and embedded in these spaces.

\subsubsection{Implications for Conceptualizing Robots}

For many of the findings, we had mixed and even contradictory results that depended much on the current stage of people's lives (e.g., when imagining the future), whether they were in the company of others and what place in the home they imagined a latest invention to be in. Regarding privacy, older adults had different concerns depending on the place in their homes. Different preferences regarding a robot were also discussed depending on whether other people were visiting or whether the older person was alone. These mixed results suggest that there is no one-size-fits-all solution possible. i.e., there may be better or worse solutions according to specific people's circumstances and context. In support of the literature, our findings are a call for systems that can be adapted and re-purposed over time [22], given changing needs and different users being involved in AAL and telecare scenarios in which robots in the home may have a role to play.

We found that older adults are open for practical support by technology in housework, which connects to previous research. For example, participants in our study said they wanted a robot to be able to lift heavy things. Previous research also indicates that trusting robots would be connected to them having practical capabilities like heavy lifting [55].

As social contact was a repeating theme that tended to be very important to most people, this also needs to be taken into account when designing robots. Being able to talk to family members for example or making contact with other people when living at home may be crucial features especially when designing for older adults. Therefore, in addition to the robot being companionable (as already suggested by the literature [55]), using robots to connect easily to other people should be a design feature of high priority, along with privacy. While expert users have proposed using robots as social proxies in previous research [19], the data from older people in our study also support this suggestion based on findings from using the deck of cards. The role of privacy was further discussed in previous research in relation to trust. Where privacy is complex and addressing it may require individual solutions (instead of one-size-fits-all), robots need to be designed to protect the privacy of older adults [50]. Older people need to have an opportunity to negotiate their privacy [50] and further to adapt it [22].

The desire for companionship and privacy however causes a potential conflict of interest, which we find especially important to take into account. Designing robots to be companionable in a way that older people are likely to attach to them (e.g., using anthropomorphic design cues) may help them to trust the robot (e.g., when they find a robot particularly cute), but this can also involve ethical risks [30]. Older people explicitly stated that they did not want to be watched at certain places. We find it therefore important to make design decisions in a way that the notion of being watched is not obfuscated, e.g. by designing cute eyes, but rather made transparent to older adults. While robots who have the capabilities to process data may be designed as companionable, people's desire for privacy needs to be given a high priority as well when designing for trust.

Control was a repeating theme, and it also represents a call for designing for better communication and the option to turn off technology easily without negative consequences. Previous research on human-robot interaction in domestic environments however suggests that the higher people's desire was to control a robot, the more autonomously they wanted it to act when performing a cleaning task [12]. Control is also related to people's technical affinity and aspects like self-efficacy in HRI [45,64], as it also requires the knowledge and appropriate expectations to be able to interact with robots. To complement previous work on trust (e.g. [64]), more research needs to be done also with older people and robots around self-efficacy in HRI and control aspects. 


\section{Limitations and Future Work}

While the study presented here argues for the potential value of the deck of cards for use by inexperienced interviewers to explore situated understandings of robots and trust in a participatory design process, we also point to limitations of our study and present future work to tackle them.

We wanted to provide a low-threshold method to enable developers and programmers of robots to become more deeply involved in understanding the interrelations of private spaces, trust and technology for older adults. So far, we only used our approach at the ideation stage and only with student researchers as proxies for inexperienced interviewers. We are aware of other participatory design approaches in HRI with older adults that could, topic-wise, achieve similar insights (e.g. [36]). However, what stays relevant for us is that these insights were generated by stakeholders who are often not involved at these early stages. Clearly, our method does not create insights which can be directly transferred to conceptualizations or prototypes, and the challenges coming with that are also addressed by fellow researchers [20]. In a next iteration, we think of how the method can be adapted and/or extended to also be used at later stages of conceptualizing, prototyping, and evaluating robotic systems. The methodological gap the cards are closing for participatory design in HRI is that they enable an easy access for technology developers to be actively engaged with potential end users (i.e., older adults) and thereby have these experiences and sensitising insights in mind when creating the technology. We propose that the cards could also be used as participatory evaluation, as the cards already revealed measures of success and/or quality relevant to end users for trustworthy robots in their homes. The fact that the cards helped revising ideas is an indication that they are also suitable for an evaluation process.

Intentionally, the cards do not come with a standardized procedure how to use them, which we consider as one of the method's strength. The reason behind this is that we wanted to offer flexibility and adaptability to untrained interviewers to find their own ways to get the most information out of the conversation, since every person (interviewer and interviewee) conversation and context is unique. For an interviewer without formal training in how to conduct interviews, the flexibility of the cards enables them to find a good strategy that works for their own style and comfort. We suggest this flexibility in application, while also scaffolded in the content and process via the card and game feature to enable participation of engineers in the ideation process that might otherwise be daunting. The open-ended nature of the approach allowed for co-constituting a narrative between the interviewer and the interviewee, also responding to individual notions of trust, specific contexts and people's everyday practices.
It can also be argued that the flexibility of the cards is also one of its weaknesses since it makes it more difficult to unpack what aspects of the cards worked in what way and therefore to provide more structured guidance to future users of the cards. For future work it will be beneficial to make a comparative study between an open-ended and a structured procedure, as well as experienced vs inexperienced interviewers to draw more generalised conclusions across participants and interviewers. Another option is to explore the use of the cards with different team members such as engineers, developers, social scientists and people who are more or less familiar with issues around robots and AAL.

We presented our findings based on qualitative research, as we chose to use an open-ended approach especially at the beginning of the design process and to leave space to negotiate values associated with trust and robots between interviewers and older adults. These values are contextdependent and need to be negotiated individually. We also chose to interview the interviewers (i.e., the students) to explore the qualities of their experiences and practical challenges in using the cards as openly as possible. Thus, our primary research goal was not to come up with generalizable findings or scientific truths. Rather, the cards are meant to establish a shared understanding of the notion of trust in the context of design. Future work may however also add questionnaires to validating our method, e.g., before and after using the cards.

The cards were created to include primary users such as senior citizens into the design process at an early stage, and we aimed to also take into account the social life of people by introducing the People Card. In future work, including 2D or 3D representations of additional people (e.g. tokens), such as flatmates, friends or caregivers, could be useful for expanding the method. Previous research also suggests that social dynamics in the home can be made more explicit with a method like collaborative map making [37]. Drawing networks of people may also be an option to facilitate more details about these social dynamics in homes. Another option is to explore using tokens or markers to visualize other people at places in the home, and include them even more explicitly in the conversations.

Future work may also aim to tackle challenges around the terminology. For example, showing visual representations of related technology has shown to be fruitful for older adults to learn about existing technologies $[4,36]$. In our method, we chose an open-ended approach and decided not to show any pictures or videos of existing technologies like robots but rather start from the places and daily routines per se, but this was with mixed results. Balancing out the familiar vs. the speculative is an ongoing methodological challenge to be addressed in future work, especially given imaginaries around robots are shaped by public opinions (as our own research suggests as well). For example, we suggest show- 
ing additional materials (e.g. via videos or with pictures on cards), since some of the interviewers successfully used places, motives and the interviewees' current situations to discuss opportunities for assistive technologies. This is however to be handled with care, because of potential biases and priming. We therefore envision the possibility to work with prototypes of existing technologies in later conceptualization phases of participatory design process, i.e., after ideation.

\section{Conclusion}

We proposed a set of elicitation cards to be used during interviews in the context of design of social robots and assistive technology in the homes of older adults. The primary goal of the cards was to enable conversations about the abstract topic of trust between older people and developers or researchers, as initial input into the design process. As evident from our own and related research, establishing a shared understanding of trust is important and should be created in early design phases to support the proper transferal of knowledge and more sensitive design decisions. To come up with a set of useful cards, we facilitated the creation of this participatory design tool in an iterative design process together with Informatics students and older adults. As a proof of concept of our method, we presented a number of findings both on how the cards were able to facilitate productive conversations between inexperienced interviewers and older adults, and on nuanced situated insights about older people's trust and robots based the use of the very same cards. Salient trust-related findings that emerged from this study were the participants' desire for control, companionship, privacy, understandability, and location-specific requirements with regards to trust. Robots have great potential to help care for older people at home, and the extent to which this potential is realised is not just a function of technology-specific features, but how the complex issue of trust is negotiated in the very personal and individual space of the home. This elicitation card method, and the preliminary findings from the study, point to some of the areas that will need to be addressed.

Acknowledgements We greatly thank Peter Fikar from the Multidisciplinary Design \& User Research Group (TU Wien), who has illustrated the final version of the cards, as presented in this article. We also thank the students from our course who were so engaged in co-creating the cards and a proof of concept of this method with us. Finally, we thank the anonymous reviewers for their valuable input. We are happy to send a digital version of the cards upon request.

Funding Open access funding provided by TU Wien (TUW). Isabel Schwaninger received funding from the TrustRobots Doctoral College, TU Wien.

\section{Declarations}

Conflict of interest The authors declare that they have no conflict of interest. The proposed method was developed and used as part of research-oriented teaching at TU Wien, which is regarded as a key approach in the training of future graduates and researchers. This might however lead to potential conflicts as the students' work needs to be marked at the end of the course. We tried to avoid this pitfall of researchoriented teaching by reassuring that the students mark is independent from the students' research findings and by providing additional exercises that the students could chose as an alternative or additionally. All participants were provided with consent forms at the time of data collection and could resign at any time from the study. Research was conducted in compliance with the ethical recommendations and requirements of TU Wien.

Open Access This article is licensed under a Creative Commons Attribution 4.0 International License, which permits use, sharing, adaptation, distribution and reproduction in any medium or format, as long as you give appropriate credit to the original author(s) and the source, provide a link to the Creative Commons licence, and indicate if changes were made. The images or other third party material in this article are included in the article's Creative Commons licence, unless indicated otherwise in a credit line to the material. If material is not included in the article's Creative Commons licence and your intended use is not permitted by statutory regulation or exceeds the permitted use, you will need to obtain permission directly from the copyright holder. To view a copy of this licence, visit http://creativecomm ons.org/licenses/by/4.0/.

\section{References}

1. Agrawal S, Yanco H (2018) Feedback methods in HRI: studying their effect on real-time trust and operator workload. In: Companion of the 2018 ACM/IEEE international conference on human-robot interaction, HRI '18. ACM, New York, NY, USA, pp 49-50. https://doi.org/10.1145/3173386.3177031

2. Alexandrakis D, Chorianopoulos K, Tselios N (2019) Insights on older adults' attitudes and behavior through the participatory design of an online storytelling platform. SpringerLink pp 465474 . https://doi.org/10.1007/978-3-030-29381-9_29

3. Alves V, Roque L (2011) A deck for sound design in games: enhancements based on a design exercise. In: Proceedings of the 8th international conference on advances in computer entertainment technology, ACE '11. ACM, New York, NY, USA, pp 34:1-34:8. https://doi.org/10.1145/2071423.2071465

4. Alves-Oliveira P, Petisca S, Correia F, Maia N, Paiva A (2015) Social robots for older adults: framework of activities for aging in place with robots. SpringerLink, pp 11-20. https://doi.org/10. 1007/978-3-319-25554-5_2

5. Ballard S, Chappell KM, Kennedy K (2019) Judgment call the game: using value sensitive design and design fiction to surface ethical concerns related to technology. In: Proceedings of the 2019 on designing interactive systems conference, DIS '19. ACM, New York, NY, USA, pp 421-433. https://doi.org/10.1145/3322276. 3323697

6. Bartneck C (2004) From fiction to science-a cultural reflection of social robots. In: Proceedings of the CHI2004 workshop on shaping human-robot interaction, pp 1-4

7. Barton KC (2015) Elicitation techniques: getting people to talk about ideas they don't usually talk about. Theory Res Soc Educ 43(2):179-205. https://doi.org/10.1080/00933104.2015.1034392 
8. Beck E, Obrist M, Bernhaupt R, Tscheligi M (2008) Instant card technique: how and why to apply in user-centered design. In: Proceedings of the tenth anniversary conference on participatory design 2008, PDC '08. Indiana University, Indianapolis, IN, USA, pp 162-165. http://dl.acm.org/citation.cfm?id=1795234.1795261

9. Bernhaupt R, Weiss A, Obrist M, Tscheligi M (2007) Playful probing: making probing more fun. Lect Notes Comput Sci 4662 LNCS(PART 1):606-619

10. Billings DR, Schaefer KE, Chen JY, Hancock PA (2012) Humanrobot interaction: developing trust in robots. In: Proceedings of the seventh annual ACM/IEEE international conference on humanrobot interaction-HRI '12. ACM Press, Boston, Massachusetts, USA, p 109. https://doi.org/10.1145/2157689.2157709

11. Bråthen H, Maartmann-Moe H, Schulz TW (2019) The role of physical prototyping in participatory design with older adults. International Academy, Research and Industry Association (IARIA), pp 141-146. https://www.duo.uio.no/handle/10852/68794

12. Chanseau A, Dautenhahn K, Koay KL, Salem M (2016) Who is in charge? Sense of control and robot anxiety in human-robot interaction. In: 2016 25th IEEE international symposium on robot and human interactive communication (RO-MAN), pp 743-748. https://doi.org/10.1109/ROMAN.2016.7745202

13. Charalambous G, Fletcher S, Webb P (2016) The development of a scale to evaluate trust in industrial human-robot collaboration. Int J Soc Robot 8(2):193-209. https://doi.org/10.1007/s12369-0150333-8

14. Cohn S (2015) Trust my doctor, trust my pancreas: trust as an emergent quality of social practice. Philos Ethics Humanit Med 10(9):9

15. Collier Jr J (1986) Visual anthropology: photography as a research method. University of New Mexico Press

16. Corbett E, Le Dantec CA (2018) Going the distance: trust work for citizen participation. In: Proceedings of the $2018 \mathrm{CHI}$ conference on human factors in computing systems, CHI '18. ACM, New York, NY, USA, pp 312:1-312:13. https://doi.org/10.1145/ 3173574.3173886

17. Crabtree A, Tolmie P, Knight W (2017) Repacking 'Privacy' for a networked world. Springer, London. https://dl.eusset.eu/handle/ $20.500 .12015 / 2865$

18. Deng Y, Antle AN, Neustaedter C (2014) Tango cards: a card-based design tool for informing the design of tangible learning games. In: Proceedings of the 2014 conference on designing interactive systems, DIS '14. ACM, New York, NY, USA, pp 695-704. https:// doi.org/10.1145/2598510.2598601

19. Dereshev D, Kirk D, Matsumura K, Maeda T (2019) Long-term value of social robots through the eyes of expert users. In: Proceedings of the $2019 \mathrm{CHI}$ conference on human factors in computing systems, CHI'19. Association for Computing Machinery, New York, NY, USA. https://doi.org/10.1145/3290605.3300896

20. Dourish P (2006) Implications for design. In: Proceedings of the SIGCHI conference on human factors in computing systems, CHI'06. Association for Computing Machinery, New York, NY, USA, pp 541-550. https://doi.org/10.1145/1124772.1124855

21. Fedosov A, Kitazaki M, Odom W, Langheinrich M (2019) Sharing economy design cards. In: Proceedings of the 2019 CHI conference on human factors in computing systems, CHI '19. ACM, New York, NY, USA, pp 145:1-145:14. https://doi.org/10.1145/ 3290605.3300375

22. Fitzpatrick G, Huldtgren A, Malmborg L, Harley D, Ijsselsteijn W (2015) Design for agency, adaptivity and reciprocity: reimagining AAL and telecare agendas. SpringerLink, pp 305-338. https://doi. org/10.1007/978-1-4471-6720-4_13

23. Forlizzi J (2018) Moving beyond user-centered design. Interactions 25(5):22-23

24. Frennert S, Eftring H, Östlund B (2013) Older people's involvement in the development of a social assistive robot. In: Proceedings of the 5th international conference on social robotics-vol 8239, ICSR 2013. Springer, Berlin, Heidelberg, pp 8-18. https://doi.org/ 10.1007/978-3-319-02675-6_2

25. Froschauer U, Lueger M (2003) Das qualitative Interview. facultas wuv, Wien, AT

26. Gompei T, Umemuro H (2018) Factors and development of cognitive and affective trust on social robots. SpringerLink, pp 45-54. https://doi.org/10.1007/978-3-030-05204-1_5

27. Güldenpfennig F, Ganglbauer E, Fitzpatrick G, Nunes F (2016) Making space to engage: an open-ended exploration of technology design with older adults. Int J Mob Hum Comput Interaction 8(2):1-19. https://doi.org/10.4018/IJMHCI.2016040101

28. Hancock PA, Billings DR, Schaefer KE, Chen JYC, de Visser EJ, Parasuraman R (2011) A meta-analysis of factors affecting trust in human-robot interaction. Hum Factors J Hum Factors Ergon Soc 53(5):517-527. https://doi.org/10.1177/0018720811417254

29. Hosking I, Cornish K, Bradley M, Clarkson PJ (2014) Empathic engineering: helping deliver dignity through design. J Med Eng Technol 39(7):388-394. https://doi.org/10.3109/03091902.2015. 1088090

30. Huber A, Weiss A, Rauhala M (2016) The ethical risk of attachment how to identify, investigate and predict potential ethical risks in the development of social companion robots. In: 2016 11th ACM/IEEE international conference on human-robot interaction (HRI). IEEE, pp 367-374

31. IDEO (2003) IDEO method cards: 51 ways to inspire design. William Stout

32. Knowles B, Hanson VL (2018) Older adults' deployment of 'distrust'. ACM Trans Comput Hum Interaction 25(4):21:1-21:25. https://doi.org/10.1145/3196490

33. Kuutti K, Bannon LJ (2014) The turn to practice in HCI: towards a research agenda. In: Proceedings of the SIGCHI conference on human factors in computing systems, CHI '14. ACM, New York, NY, USA, pp 3543-3552. https://doi.org/10.1145/2556288. 2557111

34. Lan Hing Ting K, Derras M, Voilmy D (2018) Designing humanrobot interaction for dependent elderlies: a living lab approach. In: BCS Learning and Development Ltd. Proceedings of British HCI 2018. https://doi.org/10.14236/ewic/HCI2018.142

35. Lee HR, Šabanović S (2013) Weiser's dream in the Korean home: collaborative study of domestic roles, relationships, and ideal technologies. In: Proceedings of the 2013 ACM international joint conference on pervasive and ubiquitous computing, UbiComp '13. ACM, New York, NY, USA, pp 637-646. https://doi.org/10.1145/ 2493432.2493499

36. Lee HR, Šabanović S, Chang WL, Nagata S, Piatt J, Bennett C, Hakken D (2017) Steps toward participatory design of social robots: mutual learning with older adults with depression. In: Proceedings of the 2017 ACM/IEEE international conference on human-robot interaction, HRI '17. ACM, New York, NY, USA, pp 244-253. https://doi.org/10.1145/2909824.3020237

37. Lee HR, Šabanović S, Kwak SS (2017) Collaborative map making: a reflexive method for understanding matters of concern in design research. In: Proceedings of the $2017 \mathrm{CHI}$ conference on human factors in computing systems, CHI' 17. ACM, New York, NY, USA, pp 5678-5689. https://doi.org/10.1145/3025453.3025535

38. Lewis JD, Weigert A (1985) Trust as a social reality. Soc Forces 63(4):967-985. https://doi.org/10.1093/sf/63.4.967

39. Lindsay S, Jackson D, Schofield G, Olivier P (2012) Engaging older people using participatory design. In: Proceedings of the SIGCHI conference on human factors in computing systems, CHI '12. ACM, New York, NY, USA, pp 1199-1208. https://doi.org/ $10.1145 / 2207676.2208570$

40. Martelaro A, Nneji C, Ju A, Hinds A (2016) Tell me more: designing HRI to encourage more trust, disclosure, and companionship. In: 2016 11th ACM/IEEE international conference on human- 
robot interaction (HRI), pp 577. https://doi.org/10.1109/HRI.2016. 7451864

41. Mayer RC, Davis JH, Schoorman FD (1995) An integrative model of organizational trust. Acad Manag Rev 20(3):709. https://doi.org/ $10.2307 / 258792$

42. Millen DR (2000) Rapid ethnography: time deepening strategies for HCI field research. In: Proceedings of the 3rd conference on designing interactive systems: processes, practices, methods, and techniques, DIS'00. Association for Computing Machinery, New York, NY, USA, pp 280-286. https://doi.org/10.1145/347642. 347763

43. Newaz F, Saplacan D (2020) Exploring the role of feedback on trust for the robots used in homes of the elderly. In: Proceedings of the 10th Nordic conference on human-computer interaction, pp 681-685. https://doi.org/10.1145/3240167.3240248

44. Peters D, Loke L, Ahmadpour N (2020) Toolkits, cards and games-a review of analogue tools for collaborative ideation. CoDesign, pp 1-25. https://doi.org/10.1080/15710882. 2020.1715444

45. Pütten ARVD, Bock N (2018) Development and validation of the self-efficacy in human-robot-interaction scale (SE-HRI). ACM Trans Hum Robot Interaction 7(3):21:1-21:30. https://doi.org/10. $1145 / 3139352$

46. Rossi A, Dautenhahn K, Koay KL, Saunders J (2017) Investigating human perceptions of trust in robots for safe HRI in home environments. In: Proceedings of the companion of the 2017 ACM/IEEE international conference on human-robot interaction, HRI ' 17. ACM, New York, NY, USA, pp 375-376. https://doi.org/10.1145/ 3029798.3034822

47. Salem M, Lakatos G, Amirabdollahian F, Dautenhahn K (2015) Towards safe and trustworthy social robots: ethical challenges and practical issues. SpringerLink, pp 584-593. https://doi.org/10. 1007/978-3-319-25554-5_58

48. Samani H, Saadatian E, Pang N, Polydorou D, Fernando ONN, Nakatsu R, Koh JTKV (2013) Cultural robotics: the culture of robotics and robotics in culture. Int J Adv Robot Syst. https://doi. org $/ 10.5772 / 57260$

49. Schaefer KE (2016) Measuring trust in human robot interactions: development of the "Trust Perception Scale-HRI". SpringerLink, pp 191-218. https://doi.org/10.1007/978-1-4899-7668-0_10

50. Schulz T, Herstad J, Holone H (2018) Privacy at home: an inquiry into sensors and robots for the stay at home elderly. SpringerLink, pp 377-394. https://doi.org/10.1007/978-3-319-92037-5_28

51. Schwaninger I, Fitzpatrick G, Weiss A (2019) Exploring trust in human-agent collaboration. In: Proceedings of the 17th European conference on computer-supported cooperative work: the international venue on practice-centred computing an the design of cooperation technologies-exploratory papers. https://doi.org/10. 18420/ecscw2019_ep08

52. Schwaninger I, Frauenberger C, Fitzpatrick G (2020) Unpacking forms of relatedness around older people and telecare. In: Companion publication of the 2020 on designing interactive systems conference 2020 companion, DIS'20 companion. Association for Computing Machinery, New York, NY, USA. https://doi.org/10. $1145 / 3393914.3395867$

53. Semaan B, Mark G (2011) Creating a context of trust with icts: restoring a sense of normalcy in the environment. In: Proceedings of the ACM 2011 conference on computer supported cooperative work, CSCW '11. ACM, New York, NY, USA, pp 255-264. https:// doi.org/10.1145/1958824.1958863

54. Silva PA, Daniel AD (2019) Training non-designers in co-design methods through an active assisted living interactive workshop. SpringerLink, pp 166-175. https://doi.org/10.1007/978-3-03029384-0_10
55. Stuck RE, Rogers WA (2018) Older adults' perceptions of supporting factors of trust in a robot care provider. J Robot. https://doi.org/ $10.1155 / 2018 / 6519713$

56. Sundar SS, Waddell TF, Jung EH (2016) The Hollywood robot syndrome: media effects on older adults' attitudes toward robots and adoption intentions. Penn State, pp 343-350. https://doi.org/ 10.1109/HRI.2016.7451771

57. Ullman D, Malle BF (2018) What does it mean to trust a robot?: Steps toward a multidimensional measure of trust. In: Companion of the $2018 \mathrm{ACM} / \mathrm{IEEE}$ international conference on human-robot interaction, HRI '18. ACM, New York, NY, USA, pp 263-264. https://doi.org/10.1145/3173386.3176991

58. Van House NA, Butler MH, Schiff LR (1998) Cooperative knowledge work and practices of trust: sharing environmental planning data sets. In: Proceedings of the 1998 ACM conference on computer supported cooperative work, CSCW '98. ACM, New York, NY, USA, pp 335-343. https://doi.org/10.1145/289444.289508

59. Vincze M, Bajones M, Suchi M, Wolf D, la Puente Pd (2016) Learning and detecting objects with a mobile robot to assist older adults in their homes, vol 9914, pp 316-330. https://doi.org/10. 1007/978-3-319-48881-3_22

60. Vincze M, Weiss A, Lammer L, Huber A, Gatterer G (2014) On the discrepancy between present service robots and older persons' needs. In: 23rd IEEE international symposium on robot and human interactive communication (IEEE RO-MAN 2014)

61. Wagner AR, Robinette P, Howard A (2018) Modeling the humanrobot trust phenomenon: a conceptual framework based on risk. ACM Trans Interaction Intell Syst 8(4):26:1-26:24. https://doi.org/ $10.1145 / 3152890$

62. Wang Y, Mark G (2013) Trust in online news: comparing social media and official media use by chinese citizens. In: Proceedings of the 2013 conference on computer supported cooperative work, CSCW '13. ACM, New York, NY, USA, pp 599-610. https://doi. org/10.1145/2441776.2441843

63. Wulf V (2009) Theorien sozialer Praktiken zur Fundierung der Wirtschaftsinformatik. SpringerLink, pp 211-224. https://doi.org/ 10.1007/978-3-7908-2336-3_11

64. Zafari S, Schwaninger I, Hirschmanner M, Schmidbauer C, Weiss A, Koeszegi ST (2019) 'You Are Doing so Great!'-the effect of a robot's interaction style on self-efficacy in HRI. In: Proceedings of the 28th IEEE international conference on robot and human interactive communication (ROMAN)

Publisher's Note Springer Nature remains neutral with regard to jurisdictional claims in published maps and institutional affiliations.

Isabel Schwaninger works as a University Assistant at the HumanComputer Interaction Group at the Faculty of Informatics at TU Wien in Austria. Her PhD research is on the topic of trust in Human-Robot Interaction, and she is interested in applications of assistive technology in healthcare contexts. She has worked in AAL research projects, and she has work experience as a data scientist at the Chinese Studies department at the University of Vienna and in the field of language education. She has an academic background in Software Engineering, International Development and Chinese Studies.

Florian Güldenpfennig works as a professor for interaction design at New Design University in St. Pölten (Austria). He has a particular research interest in tangible and embodied interaction. Moreover, he is interested in the theoretical as well as practical exploration of different design processes with the overarching aim to come up with novel 
designs that meet people's functional and - not less importantly - psychological and social needs.

Astrid Weiss studied sociology and earned her doctorate in social sciences at the University of Salzburg, Austria in 2010. After her doctorate she was a postdoc at the HCI \& Usability Unit, at the ICT \& S Center and at the Christian Doppler Laboratory for "Contextual Interfaces" at the University of Salzburg, Austria. She also had research stays at the University of Amsterdam (Intelligent Systems $\mathrm{Lab}$ ) and the University of Twente (Human Media Interaction Group). Currently, Astrid Weiss is Senior Researcher on Human-Computer Interaction at the Institute for Visual Computing \& Human Centered Technology at the TU Wien, Austria. Before joining the Faculty of Computer Science, Weiss worked as a FWF-Hertha-Firnberg scientist at the Vision4Robotics Group (Institute of Automation and Control, Faculty of Electrical Engineering and Information Technology, TU Wien, Austria). In 2018, she was elected as member of the Young Academy of the Austrian Academy of Sciences.

Geraldine Fitzpatrick is Professor of Technology Design and Assessment in the Informatics Faculty at TU Wien and heads the Human Computer Interaction Group. She is an ACM Distinguished Scientist, IFIP Fellow, and IFIP TC-13 Pioneer Award recipient. She has worked in academic, research and industry consultancy roles in Austria, the UK and Australia. Her research is at the intersection of social and computer sciences, with a particular interest in collaboration, health and well-being, social and emotional skills, and community building. 